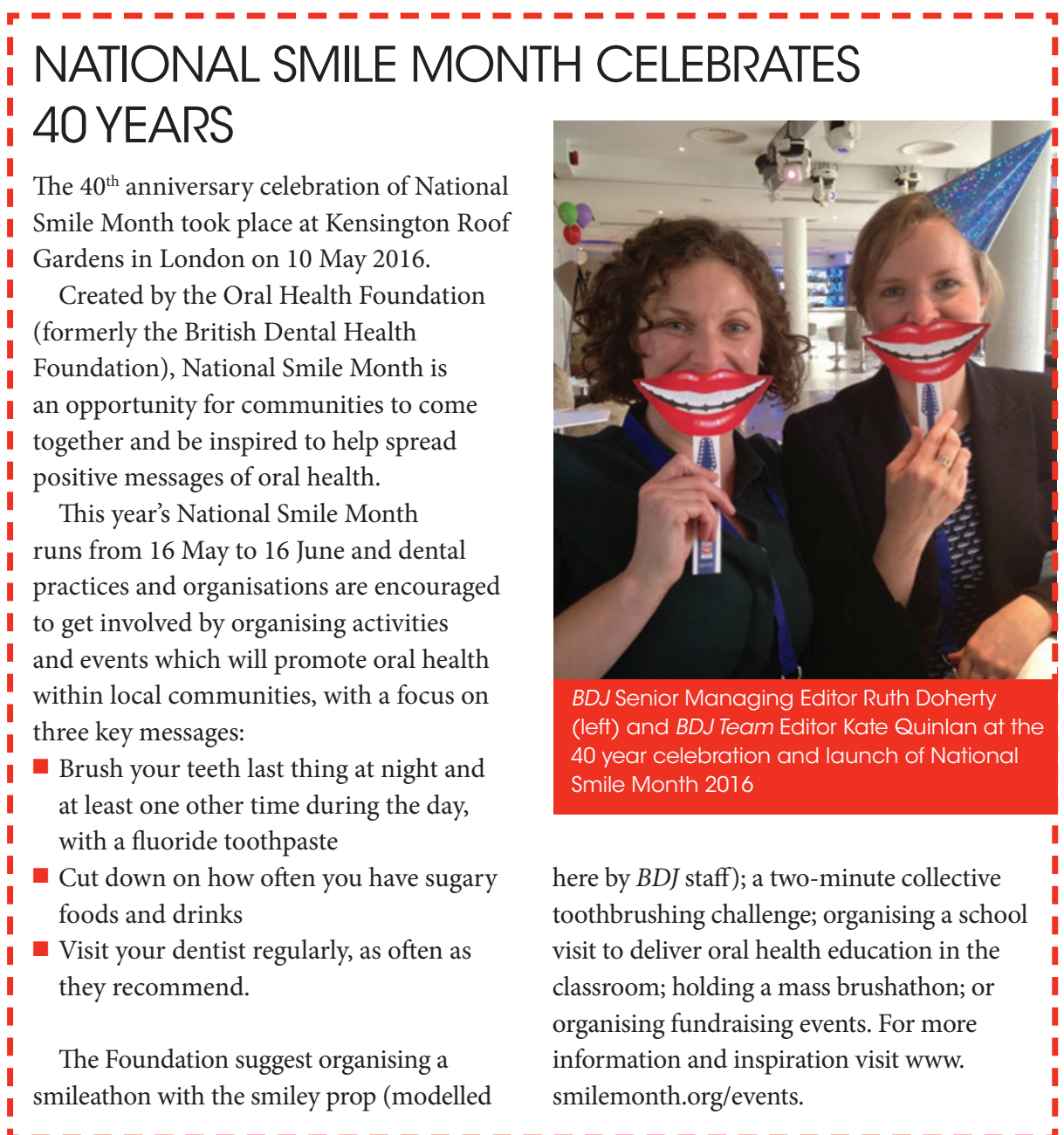

\section{FIRST SMILES INITIATIVE TO RETURN TO UK SCHOOLS}

The British Society of Dental Hygiene and Therapy (BSDHT) are thrilled to announce the return of First Smiles on Friday 17 June 2016 , an initiative aiming to bring oral health education to young children in their own classroom.

First Smiles encourages BSDHT members to enter schools and nurseries across the UK to deliver fun and accessible lessons to children regarding the importance of good oral health, and to teach them the necessary habits needed to maintain a healthy smile for life.

President of the BSDHT, Michaela ONeill, said: 'First Smiles launched last year to huge success; our amazing BSDHT members really helped to make a significant difference to children's oral health by engaging with thousands of children in classrooms across the country.

'Our members, as well as schools and nurseries across the UK, have really embraced this potentially life changing initiative; we are really proud of what we have achieved so far but there is still so much more that we think we can achieve.

'This year we want the programme to be bigger and better; we want your help to ensure important oral health messages reach many more children.'

This year the BSDHT are delighted to announce that Oral B have generously provided toothbrush and toothpaste samples to help First Smiles reach its important objectives.

The campaign is open only to dental hygienists, dental hygienist-therapists and

Whether it's their first tooth or their first visit to the dentist, a child's early experiences of oral health can impact on the rest of their lives. BSDHT members who wish to take part and make a difference can find out more about First Smiles at bsdht.org.uk/First_Smiles.

To find out more about the benefits of membership with the BSDHT visit www. bsdht.org.uk/membership. students who are BSDHT members.

\section{BSP GETS MOUTHIE ABOUT GUM DISEASE}

On 12 May this year, for the first time in its 67-year history, the British Society of Periodontology (BSP) took the bold step of launching an innovative UK-wide campaign to raise awareness of gum disease and its far-reaching impact on general health.

The BSP is using the power of social media and some eye-opening face cards to show how you could look with gum disease - providing a fun way to draw attention to gum health -which were available via the campaign website and distributed around dental practices, pubs, universities and an event at London's Westfield shopping centre.

BSP President Dr Phil Ower, who was recently interviewed in the $B D J$ (220: 382), said: 'As gum disease is a serious public health issue, affecting the quality of life of over half the population, we felt it was time to shout a little louder. We have been met with fantastic support from a variety of organisations'.

The campaign is a new departure for the BSP as it is aimed at the whole country - primarily the public, but health and dental professionals too. The message of the campaign is 'If left untreated, gum disease will wipe the smile off your face.

12 May was European Gum Health Awareness Day, part of the European Federation of Periodontology's campaign to raise awareness of gum disease across Europe, drive action and encourage people to have their gum health checked, and encourage people to participate in the campaign and spread the message.

The ultimate aim is to encourage people to visit their dentist if they suspect they may have any of the symptoms of gum disease and to visit www.howsyoursmile.co.uk for more information.

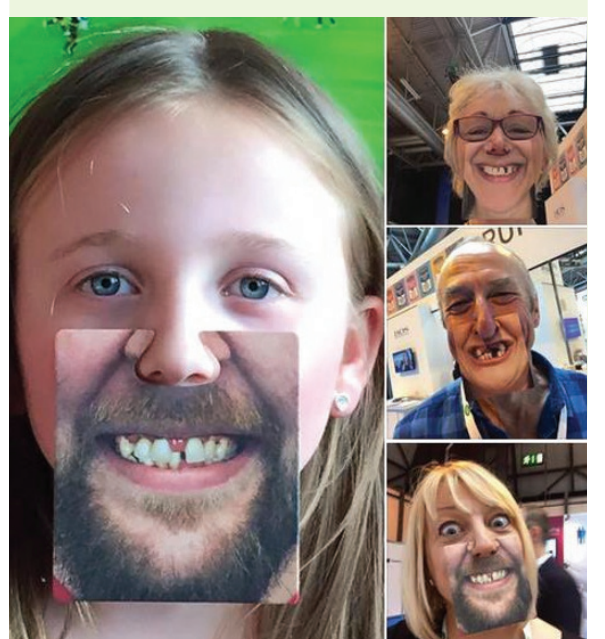

